\title{
Synthesis of ZnO Flakes on Flexible Substrate and Its Application on Ethylene Sensing at Room Temperature
}

\author{
Amalia Sholehah ${ }^{1,2, *}$, Diga Fahrezi Faroz ${ }^{1,2}$, Nurul Huda ${ }^{1,2}$, Listya Utari ${ }^{3}$, \\ Ni Luh Wulan Septiani ${ }^{3}$ and Brian Yuliarto ${ }^{3,4}[$
}

1 Advanced Materials and Tomography Laboratory, Faculty of Engineering, Universitas Sultan Ageng Tirtayasa, Jl. Jend. Sudirman Km 3, Cilegon, Banten 42435, Indonesia; digaffaroz@gmail.com (D.F.F.); nurulhuda.nh1196@gmail.com (N.H.)

2 Department of Metallurgical Engineering, Faculty of Engineering, Universitas Sultan Ageng Tirtayasa, Jl. Jend. Sudirman Km 3, Cilegon, Banten 42435, Indonesia

3 Department of Engineering Physics, Faculty of Industrial Technology, Institut Teknologi Bandung, Jl. Ganesha No. 10, Bandung, Jawa Barat 41032, Indonesia; listyautari@gmail.com (L.U.); niluhwulan@gmail.com (N.L.W.S.); brian@tf.itb.ac.id (B.Y.)

4 Research Center for Nanosciences and Nanotechnology (RCNN), Institut Teknologi Bandung, Jl. Ganesha No. 10, Bandung, Jawa Barat 41032, Indonesia

* Correspondence: amalia.sholehah@untirta.ac.id; Tel.: +62-812-120-3841

Received: 31 October 2019; Accepted: 7 December 2019; Published: 19 December 2019

\begin{abstract}
As a hormone that determinates the level of fruit ripeness, ethylene concentration monitoring plays an important role in the agricultural field. One of the techniques that can be used to detect ethylene concentration is the sensing method. Zinc oxide $(\mathrm{ZnO})$ is a multipurpose metal oxide semiconductor with a wide application in sensing area. Here, we use a $\mathrm{ZnO}$-based flexible sensor to identify the presence of ethylene gas at certain concentrations. The as-synthesized $\mathrm{ZnO}$ layers were deposited on a polyethylene terephthalate-indium doped tin oxide (PET-ITO) flexible substrate using a simple electrochemical deposition method. To enhance the performance of the ethylene sensor, a small amount of silver (Ag) was added to the seeding solution. From the study, it was revealed that the $\mathrm{ZnO}-\mathrm{Ag}$ layers were able to identify the presence of ethylene gas at the lowest concentration of $29 \mathrm{ppm}$. The most optimal result was obtained using $1 \mathrm{mM} \mathrm{Ag}$. This layer demonstrated a response of $17.2 \%$ and $19.6 \%$ of ethylene gas at concentrations of 29 and $50 \mathrm{ppm}$, with recovery times of four and eight minutes, respectively.
\end{abstract}

Keywords: $\mathrm{ZnO}$; electrochemical deposition; ethylene gas; flexible sensor

\section{Introduction}

Ethylene is the smallest plant hormone that initiates fruit ripening. The presence of ethylene gas can accelerate and improve the appearance of fruit, which can increase the taste quality. The amount of ethylene released by plants can indicate the readiness level of fruit to be harvested. However, a high concentration of ethylene gas will cause the fruit to become overripe and reduce the selling price. Therefore, the ethylene gas concentration monitoring is important in order to determine the accurate harvest time of the fruits [1].

Metal oxides are promising active materials for many applications. Current progress in the preparation of metal oxides offers unique potentials function in new capabilities devices, for instance, wearable/flexible devices, smart textiles for well-being and health monitoring, or advanced sensing design, such as work functions, surface ionization, magnetic, self-heating, and Schottky-based 
devices [2]. Moreover, metal oxides have shown a remarkable application in gas sensing, such as CO, $\mathrm{NO}$, as well as toluene gas [3-5].

Zinc oxide $(\mathrm{ZnO})$ is a versatile $\mathrm{n}$-type semiconductor with wide band-gap energy ( $3.37 \mathrm{eV}$ at $300 \mathrm{~K})$ and high exciton energy (60 meV) [6]. $\mathrm{ZnO}$ nanostructures have been utilized as several types of nanosensors. The $\mathrm{ZnO}^{\prime} \mathrm{s}$ sensing performance relies on its electrical properties which may change significantly in the presence of gas or chemical substances [7]. Based on this principle, different gas [8-12] and chemical sensors have been reported $[13,14]$. The interaction between $\mathrm{ZnO}$ and chemical gases, such as ethylene, may result in the electrical resistance value change of $\mathrm{ZnO}$. However, the high working temperature of $\mathrm{ZnO}$ makes it difficult to work in ambient temperatures [15]. Moreover, ethylene is a non-polar molecule with the high activation energy for the reaction. The high dissociation bonds of $\mathrm{C}=\mathrm{C}$ and $\mathrm{C}-\mathrm{H}$ causes difficulty in ethylene's bond breakage [16]. Various attempts have been carried out to improve the new device's sensing performance, including decorating noble metal, doping proper element and introducing heterostructures [17].

The addition of noble metals, such as platinum (Pt) [18], palladium (Pd) [19], gold ( $\mathrm{Au}$ ) [20], and silver $(\mathrm{Ag})$ [21,22], to the metal oxide structure can increase sensitivity and the selectivity. Weber et al. [19] has revealed that through spillover effect, Pd can easily enhance the response of $\mathrm{ZnO}$ NWs gas sensors. Pd is a well-known catalyst possessing $\mathrm{H}_{2}$ bond breaking abilities [19].

In our previous work, we have developed a ZnO-based sensor for ethylene gas which is used in high temperature $\left(200^{\circ} \mathrm{C}\right)$. However, this sensor has a very limited response to ethylene gas. In this study, we present a flexible $\mathrm{ZnO}$ sensor which is capable of detecting ethylene gas concentration at room temperature. The $\mathrm{ZnO}$ layer is prepared using a simple electrodeposition method. This method is selected due to its advantages of being relatively inexpensive and easy to control, making it possible to implement at a mass-production scale. The effect of silver addition on the sensor performance is also investigated.

\section{Materials and Methods}

Prior to the deposition process, $2 \times 1.3 \mathrm{~cm}^{2}$ polyethylene terephthalate-indium doped tin oxide (PET-ITO) substrates (Solaronix, Aubonne, Switzerland) were firstly cleaned using an ultrasonic bath (Krisbow, Shanghai, China) in water and ethanol, consecutively. The $\mathrm{ZnO}$ precursor solution was prepared using an equimolar mixture of $0.2 \mathrm{M}$ zinc nitrate tetrahydrate $\left(\mathrm{Zn}\right.$-nitrate, $\mathrm{Zn}\left(\mathrm{NO}_{3}\right)_{2} \cdot 4 \mathrm{H}_{2} \mathrm{O}$, Merck, Darmstadt, Germany) and hexamethylenetetramine (HMTA, $\mathrm{C}_{6} \mathrm{H}_{12} \mathrm{~N}_{4}$, Merck, Darmstadt, Germany). The doping process was carried out by adding $\mathrm{AgNO}_{3}$ with the concentrations of 0.1, $0.5,1$, and $2 \mathrm{mM}$ in the precursor, which are denoted as $\mathrm{ZnO}-\mathrm{Ag} 0.1, \mathrm{ZnO}-\mathrm{Ag} 0.5, \mathrm{ZnO}-\mathrm{Ag} 1$, and $\mathrm{ZnO}-\mathrm{Ag} 2$, respectively. The solutions were further aged for $2 \mathrm{~h}$ before deposition process on the PET-ITO substrate.

The electrodeposition process was conducted at $8-10^{\circ} \mathrm{C}$, by using voltage of 1.2 volts. The PET-ITO was placed in the anode position and dipped vertically in the precursor solution. The copper $(\mathrm{Cu})$ electrode was used as the cathode. After $2 \mathrm{~h}$, the PET-ITO substrates were removed from the solution, cleaned with demineralized water, and dried in air. The area of the $\mathrm{ZnO}-\mathrm{Ag}$ sensing layer for each PET-ITO substrate was $1.3 \times 1.3 \mathrm{~cm}^{2}$. The silver paste was drawn at the tip of the sensing layer and functioned as the electrode for the sensor. The schematic figure of the sensor device with the electrode and sensing layer is shown in Figure 1a, and the flexible ZnO-based ethylene sensor is presented in Figure 1b. The phase identification of the sample deposited on the glass substrate was investigated using $\mathrm{X}$-ray diffractometer for thin films using $\mathrm{Cu}-\mathrm{K} \alpha$ radiation $(\lambda=1.5406 \AA)$ (XRD, Pan Analytical-Empyrean, Almelo, Netherlands) and Fourier transform infrared spectroscopy (FTIR, Bruker Alpha-T-Massachusetss, Billerica, MA, USA), while morphological and distributional observation was performed using scanning electron microscopy-energy-dispersive $\mathrm{x}$-ray spectroscopy (SEM-EDS, Hitachi SU3500, Tokyo, Japan).

To measure gas-sensing properties, the test sample was placed in a sealed chamber. The resistance value of $\mathrm{ZnO}$ film (i.e., $R_{a}$ ) in air was measured thereafter. The ethylene gas was then injected into the 
sample chamber and the resistance of the sample in the presence of ethylene gas (i.e., $R_{g}$ ) was measured by Picotest M3500A digital multimeter. In this study, we use two different ethylene concentrations, i.e., 29 and 50 ppm. The schematic figure of sensor test system is presented in Figure 2. The sensor response $(S)$ to ethylene gas is defined by Equation (1) [10].

$$
S=\left(\left(R_{a}-R_{g}\right) / R_{a}\right) \times 100 \%
$$

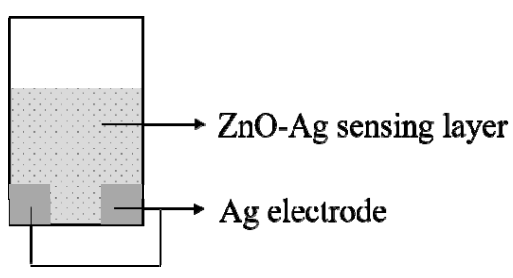

(a)

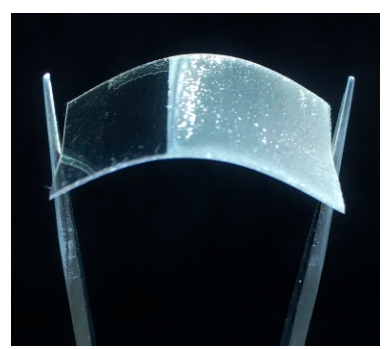

(b)

Figure 1. ZnO-based ethylene sensor: (a) Schematic design; (b) Flexible sensor.

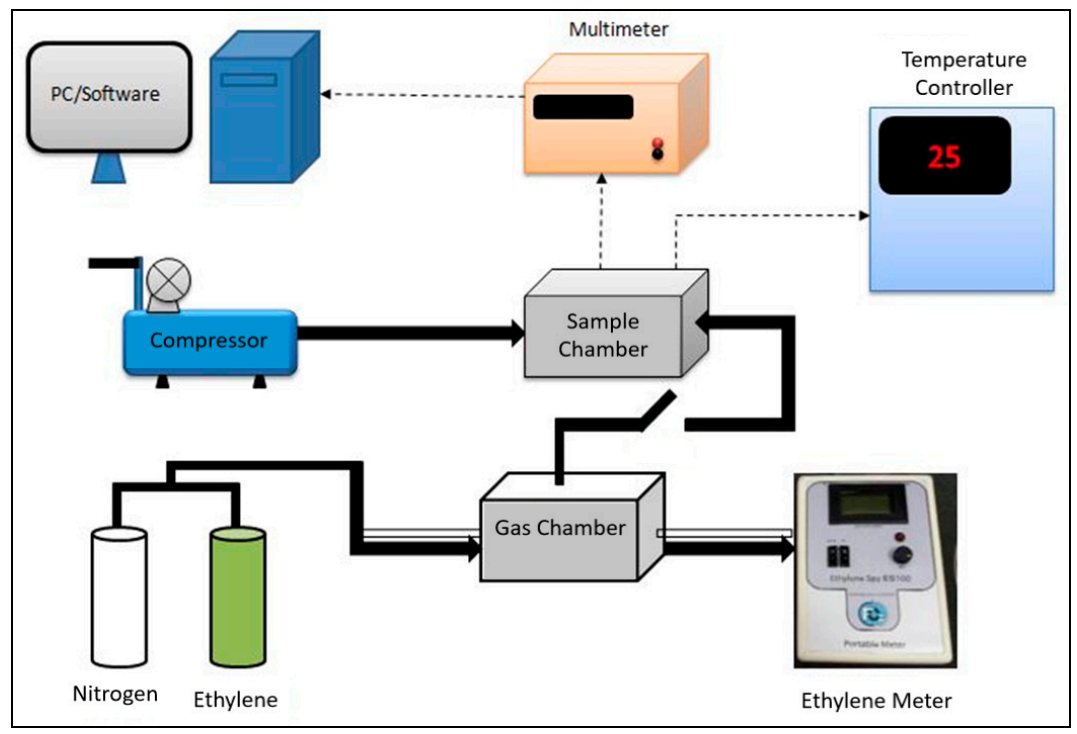

Figure 2. Ethylene sensor performance testing scheme.

\section{Results and Discussion}

\subsection{Structure and Morphologies of $\mathrm{ZnO}-A g$ Layer}

The structural information of the ZnO-Ag layers was analyzed using the XRD method. Figure 3 shows the diffraction patterns of the $\mathrm{ZnO}-\mathrm{Ag}$ layers on top of the PET-ITO substrate. Based on the patterns, the $\mathrm{ZnO}$ peak was characterized at $2 \theta \sim 31.7^{\circ}, 33.6^{\circ}$, and $34.6^{\circ}$, which correlates to the Miller index of (100), (111), and (002), respectively. The Ag peak was detected at $2 \theta \sim 37^{\circ}$ which correlates to the Miller index of (111). As seen in the diffractogram, the addition of Ag in the layer changes the layer's performance but does not increase the intensity of Ag in the pattern. Quantitative analysis was carried out to obtain the $\mathrm{ZnO}$ crystallite size in the sample. From the table, it can be seen that the addition of $\mathrm{Ag}$ in various concentrations did not have significant effect in the crystallite size. The $\mathrm{ZnO}-\mathrm{Ag}$ layers have an average crystallite size of $44 \sim 47 \mathrm{~nm}$. The crystallite size of the $\mathrm{ZnO}$ was calculated using the Debye-Scherrer method [23] (Equation (2)) and presented in Table 1.

$$
D=(0.9 \lambda) / \beta \cos \theta
$$




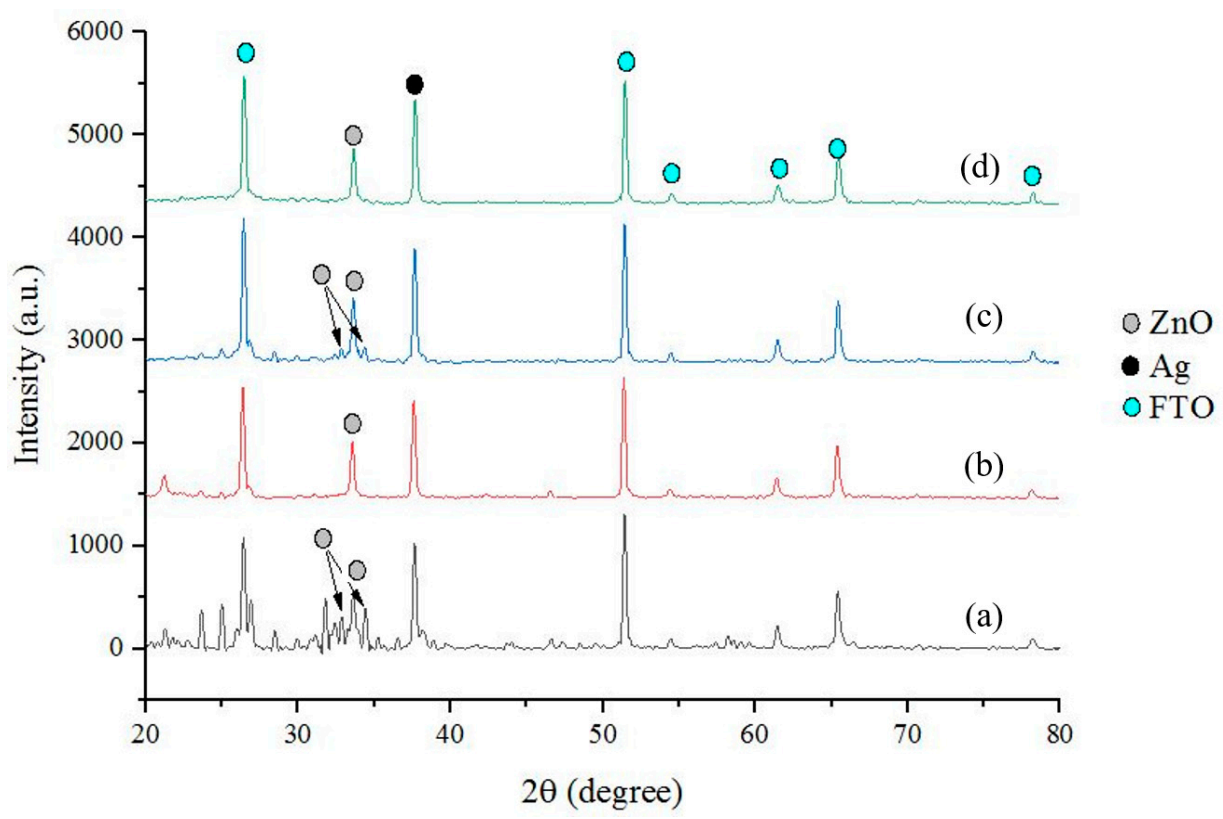

Figure 3. Diffraction pattern of: (a) ZnO-Ag0.1; (b) ZnO-Ag0.5; (c) ZnO-Ag1; and (d) ZnO-Ag2.

Table 1. The crystallite size of $\mathrm{ZnO}-\mathrm{Ag}$ layers.

\begin{tabular}{ccc}
\hline No. & Sample & Crystallite Size (nm) \\
\hline 1 & ZnO-Ag0.1 & 45.5 \\
2 & ZnO-Ag0.5 & 44.5 \\
3 & ZnO-Ag1 & 45.5 \\
4 & ZnO-Ag2 & 47.6 \\
\hline
\end{tabular}

From the table, it can be seen that the addition of Ag in various concentrations do not have significant effect in the crystallite size. The $\mathrm{ZnO}-\mathrm{Ag}$ layers have an average crystallite size of $44 \sim 47 \mathrm{~nm}$.

The attachment of $\mathrm{ZnO}$ layer could lead to the development of cracks and buckles on flexible substrate. This buckling phenomena occurs due to the compressive strains, which resulted from the substrate contraction perpendicular to the tensile direction. For $\mathrm{ZnO}$ layer, the buckles were relatively small and cracked which points to good adhesion to the PET [24].

The addition of silver doping to the $\mathrm{ZnO}$ layer using the electrodeposition method allows for the occurrence of chemical bonds between $\mathrm{ZnO}$ and Ag. To observe this, characterization using Fourier transform infrared (FTIR) spectroscopy was carried out. The FTIR spectrum of the ZnO-Ag samples is presented in Figure 4.

In Figure 4, it is observed that the $\mathrm{Zn}-\mathrm{O}$ spectrum is assigned at $500 \mathrm{~cm}^{-1}$, whereas the peaks at $800 \mathrm{~cm}^{-1}$ and $1500 \mathrm{~cm}^{-1}$ are assigned to C-H, C-O-C and C-C-O groups from the PET substrate. At $1750 \mathrm{~cm}^{-1}$, a peak that represents the $\mathrm{C}=\mathrm{O}$ group is also figured from the polyethylene substrate. Based on observations of the results of the FTIR above, one can see that there is no observed bond between $\mathrm{ZnO}$ and $\mathrm{Ag}$, which indicates that $\mathrm{ZnO}$ and $\mathrm{Ag}$ do not bind chemically [25]. The absence of chemical bonds between $\mathrm{ZnO}-\mathrm{Ag}$ indicates that $\mathrm{Ag}$ only physically binds with $\mathrm{ZnO}$ [26].

The morphology and the cross-sectional view of the $\mathrm{ZnO}-\mathrm{Ag}$ layer were analyzed using SEM, as shown in Figure 5. From the images, it was observed that using electrodeposition, the as-deposited $\mathrm{ZnO}$ was grown in flakes structure, with a size range of 10-20 $\mu \mathrm{m}$. The $\mathrm{ZnO}-\mathrm{Ag}$ layers were evenly distributed on the substrates, with a thickness range of 18-52 $\mu \mathrm{m}$. Clearer images of $\mathrm{Ag}$ in the $\mathrm{ZnO}$ layer are presented in Figures S1-S4. From the images, it is shown that Ag particles were spread on the surface of $\mathrm{ZnO}$. The mapping of Ag particles in the layers can be found in the Figure S5. 


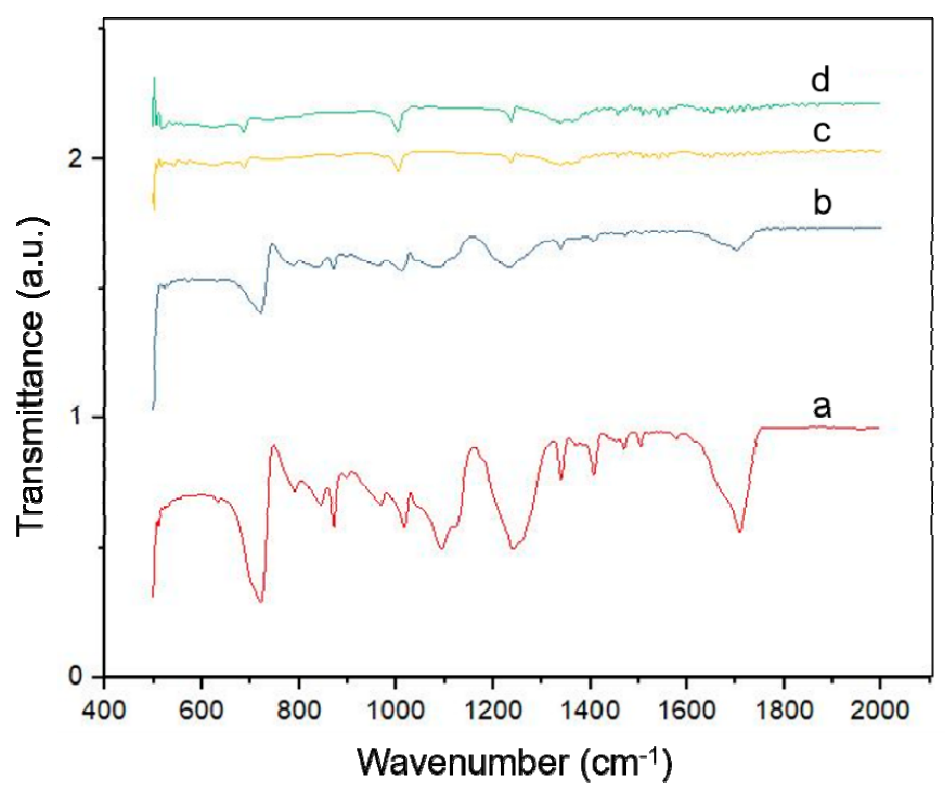

Figure 4. FTIR spectra of: (a) ZnO-Ag0.1; (b) ZnO-Ag0.5; (c) ZnO-Ag1; and (d) ZnO-Ag2.
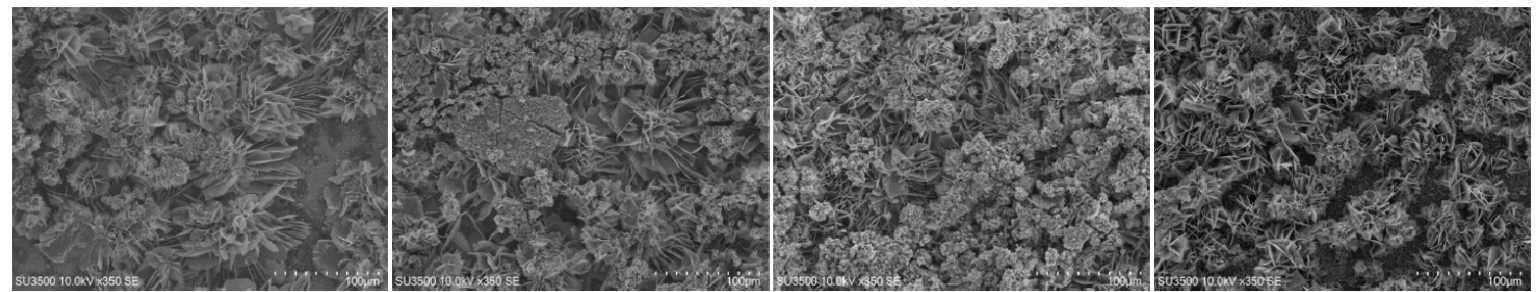

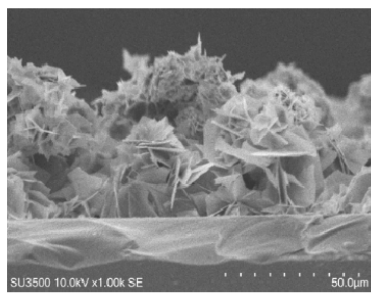

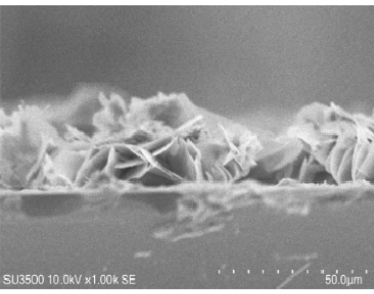

b

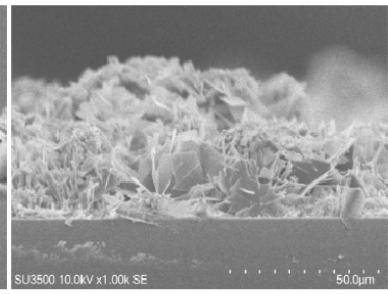

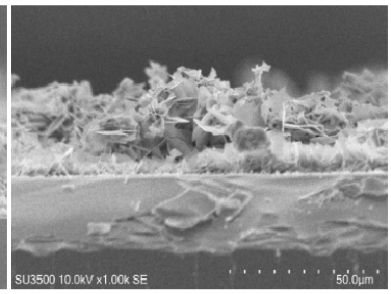

Figure 5. Top view and cross-sectional image of: (a) ZnO-Ag0.1; (b) ZnO-Ag0.5; (c) ZnO-Ag1; and (d) $\mathrm{ZnO}-\mathrm{Ag} 2$.

The amount of Ag on the surface of $\mathrm{ZnO}$ was observed using EDS. This observation was carried out to confirm the presence $\mathrm{Ag}$ on the surface of $\mathrm{ZnO}$, as compared to the addition of concentration to the electrodeposition solution. Based on in Figure S5, it was observed that a greater Ag concentration in the solution will result in a higher peak of Ag in the EDS spectrum. As shown in the figure, it is confirmed that a greater Ag concentration in the electrodeposition solution will result in a greater the wt.\% of the layer. In addition to Ag wt.\%, it is necessary to investigate the distribution of Ag in the zinc oxide layer. This will affect the spillover effect on the adsorption process of ethylene and oxygen gas in the zinc oxide layer.

Figure 6 shows the SEM-EDS mapping image from the $\mathrm{ZnO}-\mathrm{Ag}$ layers. It was observed that on $\mathrm{ZnO}$ samples with $0.1 \mathrm{mM} \mathrm{Ag}$ and $0.5 \mathrm{mM} \mathrm{Ag}$ (Figure 6a,b), the silver was spread evenly throughout the surface. On the $\mathrm{ZnO}$ layer with $1 \mathrm{mM} \mathrm{Ag}$ concentration, it was observed several spots of silver agglomerates in the layer. However, in a $2 \mathrm{mM} \mathrm{Ag} \mathrm{ZnO}$ sample, the silver tends to agglomerate in the larger areas at the surface coverage. Hence, at this concentration, the distributions of the Ag particle in $\mathrm{ZnO}$ layer is worse compared to other concentrations. The series of SEM-EDS mapping for $\mathrm{ZnO}-\mathrm{Ag}$ layers can be seen in Figure S6. 

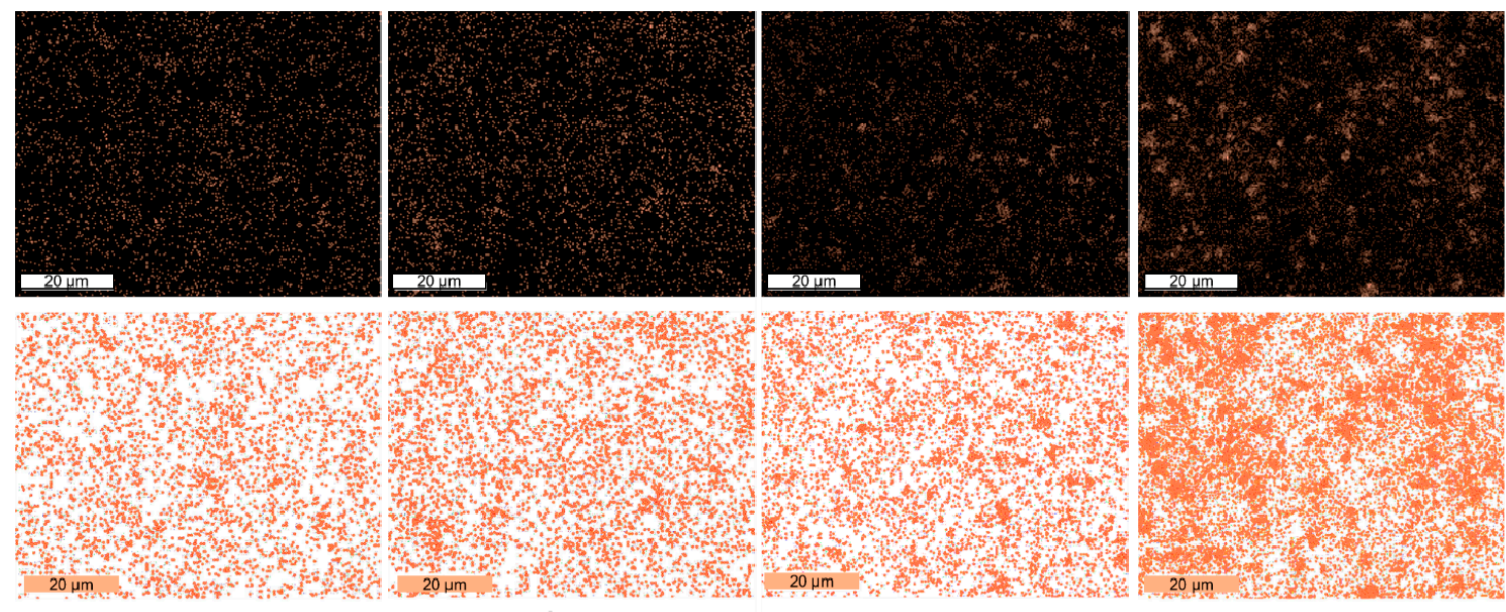

b

c

d

Figure 6. Ag distribution on $\mathrm{ZnO}$ surface in: (a) ZnO-Ag0.1; (b) ZnO-Ag0.5; (c) ZnO-Ag1; and (d) ZnO-Ag2.

\subsection{Sensor Response Test}

Sensor testing was carried out using all $\mathrm{ZnO}$ samples with 29 and 50 ppm of ethylene gas. In this study, the lowest ethylene concentration that can be detected by the ZnO-Ag sensor is $29 \mathrm{ppm}$. Meanwhile, in our previous study, the lowest ethylene concentration that could be detected by $\mathrm{ZnO}$ sensor was $50 \mathrm{ppm}$, with the sensitivity of $2.4 \%$ at $200{ }^{\circ} \mathrm{C}$ [27]. Sensor response values for $\mathrm{ZnO}-\mathrm{Ag}$ samples were found to escalate with the increase of Ag concentration. This is due to Ag doping in the material which facilitates the transfer of electrons from the valence band to the conduction band when a reaction occurs between the layer and ethylene gas. However, the $\mathrm{ZnO}$ layer with $2 \mathrm{mM} \mathrm{Ag}$ doping has shown a decline response. This is due to the conductive properties of Ag which lowered the electrical resistance of the layer. Hence, the change in resistance value becomes insignificant when the layer is exposed to ethylene gas. The graphical sensor response test can be seen in Figure 7 . The results of the sensor test response can be seen in Table 2.

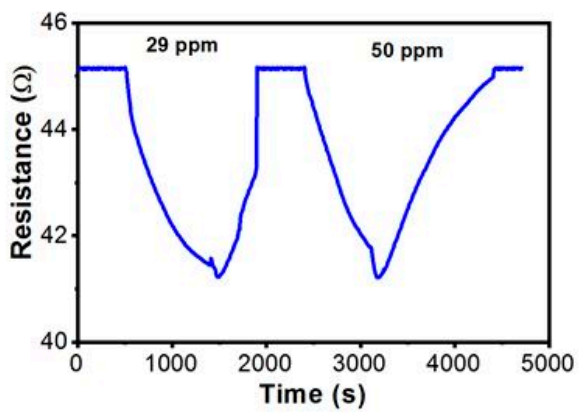

(a)

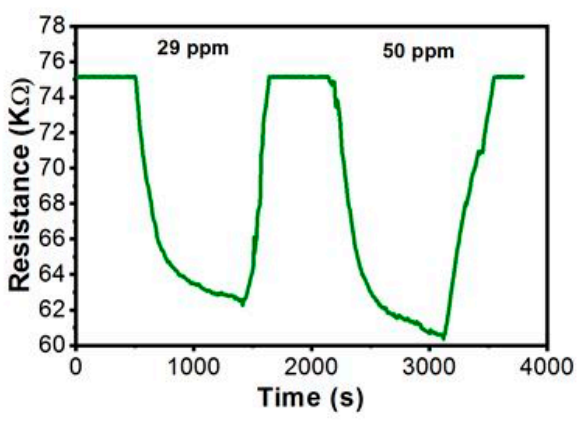

(c)

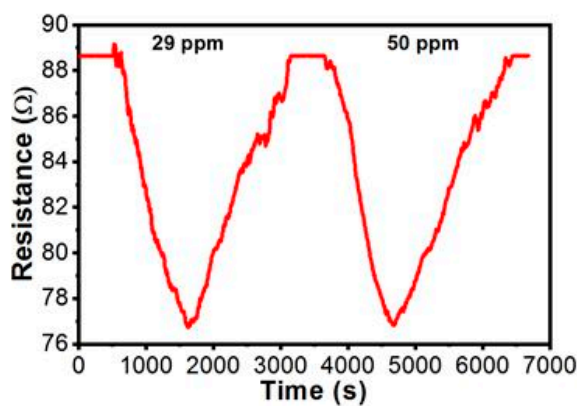

(b)

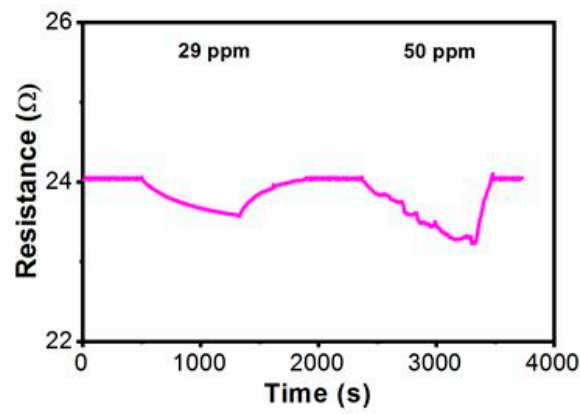

(d)

Figure 7. Sensor response on ethylene gas for: (a) ZnO-Ag0.1, (b) ZnO-Ag0.5, (c) ZnO-Ag1, and (d) ZnO-Ag2. 
Table 2. Sensor response to ethylene gas.

\begin{tabular}{ccccc}
\hline \multirow{2}{*}{ Sample } & \multicolumn{2}{c}{ Response (\%) } & \multicolumn{2}{c}{ Recovery Time (min) } \\
\cline { 2 - 5 } & $\mathbf{2 9} \mathbf{~ p p m}$ & $\mathbf{5 0} \mathbf{~ p m}$ & $\mathbf{2 9} \mathbf{~ p p m}$ & $\mathbf{5 0} \mathbf{~ p m}$ \\
\hline $\mathrm{ZnO}-0.1 \mathrm{mM} \mathrm{Ag}$ & 8.6 & 8.7 & 8 & 20 \\
$\mathrm{ZnO}-0.5 \mathrm{mM} \mathrm{Ag}$ & 13.4 & 14.2 & 29 & 32 \\
$\mathrm{ZnO}-1 \mathrm{mM} \mathrm{Ag}$ & 17.2 & 19.6 & 4 & 8 \\
$\mathrm{ZnO}-2 \mathrm{mM} \mathrm{Ag}$ & 2.1 & 3.5 & 9 & 4 \\
\hline
\end{tabular}

In the previous work, Kumar et al. [28] and Majumdar et al. [29] have shown that crystallite size and crystallinity of the sensing layer have certain effect on the sensor's performance. However, in this study, the ZnO-Ag layers had no significance difference in the crystallite size. Hence, the sensor performances are mainly dependent on the amount of $\mathrm{Ag}$ in the $\mathrm{ZnO}$ sensing layer.

These results indicate that the ethylene gas can be detected efficiently at room temperature using the $\mathrm{ZnO}-\mathrm{Ag}$ sensor. After ethylene gas flowed for $15 \mathrm{~min}$, the most significant decrease in resistance occurred in the $1 \mathrm{mM} \mathrm{Ag}$ sample reaching $14 \mathrm{~K} \Omega$, while the decrease in $\mathrm{ZnO} 2 \mathrm{mM}$ sample resistance was only $0.5 \Omega$. Furthermore, the fastest recovery time occurred in the sample of $1 \mathrm{mM} \mathrm{Ag}$, i.e., $4 \mathrm{~min}$ at $29 \mathrm{ppm}$ ethylene gas exposure. Meanwhile, $\mathrm{ZnO}$ layer $0.5 \mathrm{mM} \mathrm{Ag}$ doping also showed a good sensor response. However, this layer has the slowest recovery time. This condition might have occurred due to the structure of the $\mathrm{ZnO}-\mathrm{Ag}$ flake layer, which inhibits the release of adsorbed ethylene and prevents the $\mathrm{ZnO}$ recovery reactions with oxygen [30]. Furthermore, the addition of $\mathrm{Ag}$ to $\mathrm{ZnO}$ has been proven to lower the sensors' working temperature, while increasing the sensitivity. The effect of gas concentration started to observe when the amount of Ag doping is $1 \mathrm{mM}$, as seen in Figure 8. Below that concentration, the presence of $\mathrm{Ag}$ in $\mathrm{ZnO}$ did not seem to affect to the change of gas concentration.

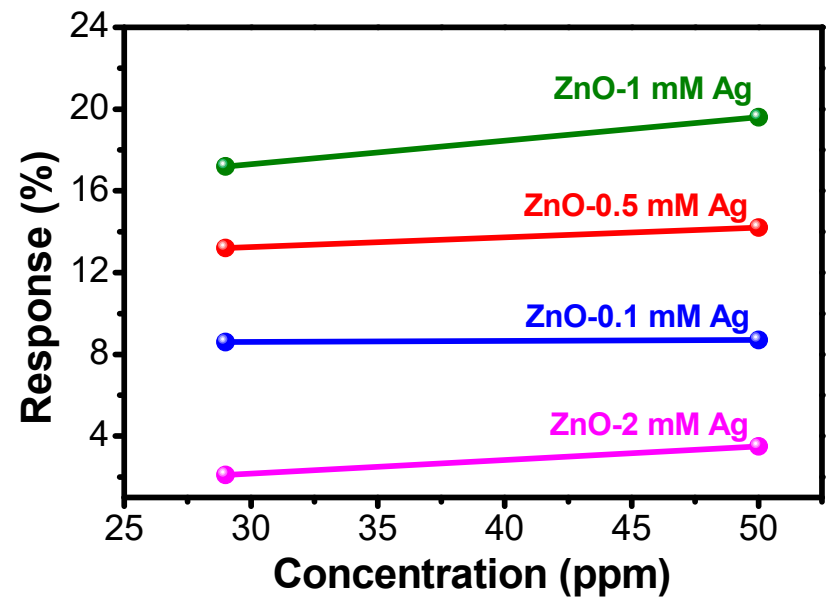

Figure 8. Effect of ethylene concentration on the response value of all $\mathrm{ZnO}-\mathrm{Ag}$ samples.

The adsorption of molecules and oxygen atoms on the surface of $\mathrm{ZnO}$ nanoparticles will produce a layer of depletion. A depletion layer forms when electrons were taken by oxygen from the conduction band of $\mathrm{ZnO}$. By taking those electrons, the oxygen will be ionized into $\mathrm{O}^{-}, \mathrm{O}_{2}{ }^{-}$, or $\mathrm{O}^{2-}$. The depletion layer prevents electrons from moving, and hence increases the electrical resistance. The more oxygen adsorbed, the greater the thickness of the depletion layer which will increase of the initial resistance before ethylene gas is flowed [31]. The ethylene gas will be adsorbed chemically (chemisorption) by zinc oxide and react with oxygen ions and electrons will switch back the conduction band so that the depletion layer will be thinned out. This will cause a decrease in electrical resistance. The amount of oxygen adsorbed is influenced by the morphology, particle size, specific surface area, and active surface area [31]. An illustration for the ethylene sensing mechanism of the $\mathrm{ZnO}-\mathrm{Ag}$ active layer is shown in Figure 9. 


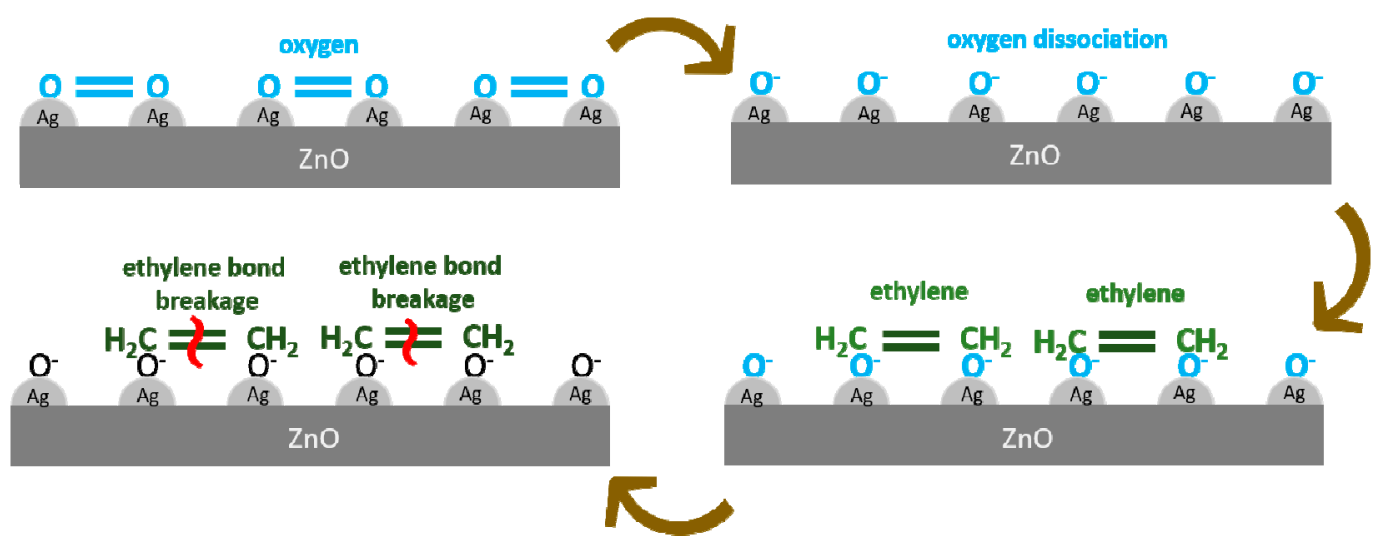

Figure 9. Sensing mechanism illustration of ethylene detection by $\mathrm{ZnO}-\mathrm{Ag}$ active layer.

Noble metals, such as Au and Ag, exhibit a surface plasmon resonance (SPR) phenomenon in the visible region due to the collective oscillations of their free electrons. The addition of Ag will generate an SPR phenomenon on the $\mathrm{ZnO}$ layer, which can accelerate the dissociation of $\mathrm{O}_{2}$ to $\mathrm{O}^{-}$on top of the layer. Thus, the oxygen ions will be more rapidly adsorbed on the surface of zinc oxide. When ethylene gas flows, silver will accelerate ethylene breakdown with the SPR phenomenon. Subsequently, the electron will return to the conduction band. Ethylene will react faster with oxygen ions, which are adsorbed on the zinc oxide surface [16].

The catalyst phenomenon that occurs in $\mathrm{ZnO}-\mathrm{Ag}$ must be accompanied by a good dispersion of precious metals on the metal oxide surface [32]. The addition of Ag must be carried out evenly on the surface of $\mathrm{ZnO}$, thus the transfer of oxygen ions to the surface of zinc oxide can be supported by spillover effects. In the $\mathrm{ZnO}$ sample with $2 \mathrm{mM} \mathrm{Ag} \mathrm{doping,} \mathrm{the} \mathrm{distribution} \mathrm{layer} \mathrm{was} \mathrm{uneven} \mathrm{or}$ concentrated at one point, which results in the spillover effect that did not occur well. In addition, the conductive $\mathrm{Ag}$ properties caused a low initial resistance before ethylene gas flowed $\left(\mathrm{R}_{0}\right)$. Consequently, the resistance changes that occur are not significant, which leads to a low sensor response in the $\mathrm{ZnO}$ $2 \mathrm{mM}$ Ag sample.

\section{Conclusions}

In this study, a flexible room-temperature ethylene sensor has been successfully fabricated using a PET-ITO substrate. The sensing layers were made using $\mathrm{ZnO}-\mathrm{Ag}$ layer, with various Ag concentrations. From the results, it was found that the optimum layer was made of $\mathrm{ZnO}$ with $1 \mathrm{mM} \mathrm{Ag}$ doping. This layer demonstrated a response of $16.8 \%$ and $17.6 \%$ of ethylene gas at 29 and 50 ppm concentrations for 15 min exposure time, with recovery times of four and eight minutes, respectively.

Supplementary Materials: The following are available online at http://www.mdpi.com/2227-9040/8/1/2/s1, Figure S1: Morphological image of $\mathrm{ZnO}$ layer with the addition of $0.1 \mathrm{mM}$ Ag. The white dots indicate Ag on the surface of $\mathrm{ZnO}$ layer, Figure S2: Morphological image of $\mathrm{ZnO}$ layer with the addition of $0.5 \mathrm{mM} \mathrm{Ag}$. The white dots indicate Ag on the surface of ZnO layer, Figure S3: Morphological image of ZnO layer with the addition of $1 \mathrm{mM}$ $\mathrm{Ag}$. The white dots indicate Ag on the surface of ZnO layer, Figure S4: Morphological image of ZnO layer with the addition of $2 \mathrm{mM} \mathrm{Ag}$. The white dots indicate Ag on the surface of ZnO layer, Figure S5: Energy-dispersive spectra for: (a) ZnO-Ag0.1; (b) ZnO-Ag0.5; (c) ZnO-Ag1; and (d) ZnO-Ag2, Figure S6: Elements distribution for: (a) ZnO-Ag0.1; (b) ZnO-Ag0.5; (c) ZnO-Ag1; and (d) ZnO-Ag2.

Author Contributions: A.S. was responsible for conceptualization, methodology, manuscript preparation, and project administration. D.F.F. contributed to the experimental laboratory work, integrity of the analytical data, and original manuscript preparation. N.H., L.U., and N.L.W.S. contributed to the experimental laboratory work, data management, data validation, visualization and data interpretation. B.Y. was responsible for conceptualization, supervision, and final manuscript revision. All authors have read and agreed to the published version of the manuscript.

Funding: This research was partly supported by the Ministry of Research, Technology, and Higher Education of Republic of Indonesia through Post-Doctoral Research Grant and Institut Teknologi Bandung (ITB). 
Acknowledgments: The authors thank Karla Karmala from Departement of Metallurgical Engineering, Faculty of Engineering, Universitas Sultan Ageng Tirtayasa for sample preparations.

Conflicts of Interest: The authors declare no conflict of interest.

\section{References}

1. Esser, B.; Schnorr, J.M.; Swager, T.M. Selective detection of ethylene gas using carbon nanotube-based devices: Utility in determination of fruit ripeness. Angew. Chem. Int. Ed. 2012, 51, 5752-5756. [CrossRef] [PubMed]

2. Comini, E. Metal oxide nanowire chemical sensors: Innovation and quality of life. Mater. Today 2016, 19, 559-567. [CrossRef]

3. Nugraha, A.; Saputro, A.G.; Agusta, M.K.; Yuliarto, B.; Dipojono, H.K.; Rusydi, F.; Maezono, R. Selectivity of CO and $\mathrm{NO}$ adsorption on $\mathrm{ZnO}$ (0002) surfaces: A DFT investigation. Appl. Surf. Sci. 2017, 410, 373-382. [CrossRef]

4. Debataraja, A.; Muchtar, A.R.; Septiani, N.L.W.; Yuliarto, B.; Nugraha; Sunendar, B. High performance carbon monoxide sensor based on nano composite of $\mathrm{SnO}_{2}$-graphene. IEEE Sens. J. 2017, 17, 8297-8305. [CrossRef]

5. Septiani, N.L.W.; Yuliarto, B.; Nugraha; Dipojono, H.K. Multiwalled carbon nanotubes-zinc oxide nanocomposites as low temperature toluene gas sensor. Appl. Phys. A 2017, 123, 166. [CrossRef]

6. Galstyan, V.; Comini, E.; Baratto, C.; Faglia, G.; Sberveglieri, G. Nanostructured ZnO chemical gas sensors. Ceram. Int. 2015, 41, 14239-14244. [CrossRef]

7. Celik-Butler, Z.; Hamid, H.M.A. ZnO nano-sensors and nano-energy harvesters. In Proceedings of the 2017 IEEE Sensors, Glasgow, UK, 29 October-1 November 2017; pp. 1-3.

8. Acharyya, D.; Bhattacharyya, P. Alcohol sensing performance of $\mathrm{ZnO}$ hexagonal nanotubes at low temperatures: A qualitative understanding. Sens. Actuators B Chem. 2016, 228, 373-386. [CrossRef]

9. Biasotto, G.; Ranieri, M.G.A.; Foschini, C.; Simões, A.Z.; Longo, E.; Zaghete, M.A. Gas sensor applications of zinc oxide thin film grown by the polymeric precursor method. Ceram. Int. 2014, 40, 14991-14996. [CrossRef]

10. Gurav, K.V.; Deshmukh, P.R.; Lokhande, C.D. LPG sensing properties of Pd-sensitized vertically aligned ZnO nanorods. Sens. Actuators B Chem. 2011, 151, 365-369. [CrossRef]

11. Rout, C.S.; Raju, A.R.; Govindaraj, A.; Rao, C.N.R. Hydrogen sensors based on ZnO nanoparticles. Solid State Commun. 2006, 138, 136-138. [CrossRef]

12. Zheng, Z.Q.; Yao, J.D.; Wang, B.; Yang, G.W. Light-controlling, flexible and transparent ethanol gas sensor based on ZnO nanoparticles for wearable devices. Sci. Rep. 2015, 5, 11070. [CrossRef] [PubMed]

13. Wang, Z.; Zhan, X.; Wang, Y.; Muhammad, S.; Huang, Y.; He, J. A flexible UV nanosensor based on reduced graphene oxide decorated $\mathrm{ZnO}$ nanostructures. Nanoscale 2012, 4, 2678. [CrossRef] [PubMed]

14. Yang, H.; Ye, Q.; Zeng, R.; Zhang, J.; Yue, L.; Xu, M.; Qiu, Z.; Wu, D. Stable and fast-response capacitive humidity sensors based on a ZnO nanopowder/PVP-RGO multilayer. Sensors. 2017, 17, 2415. [CrossRef] [PubMed]

15. Kumar, R.; Al-Dossary, O.; Kumar, G.; Umar, A. Zinc oxide nanostructures for $\mathrm{NO}_{2}$ gas-sensor applications: A review. Nano-Micro Lett. 2015, 7, 97-120. [CrossRef]

16. Liang, X.; Wang, P.; Li, M.; Zhang, Q.; Wang, Z.; Dai, Y.; Zhang, X.; Liu, Y.; Whangbo, M.; Huang, B. Adsorption of gaseous ethylene via induced polarization on plasmonic photocatalyst $\mathrm{Ag} / \mathrm{AgCl} / \mathrm{TiO}{ }_{2}$ and subsequent photodegradation. Appl. Catal. B Environ. 2018, 220, 356-361. [CrossRef]

17. Qu, Z.; Fu, Y.; Yu, B.; Deng, P.; Xing, L.; Xue, X. High and fast $\mathrm{H}_{2} \mathrm{~S}$ response of $\mathrm{NiO} / \mathrm{ZnO}$ nanowire nanogenerator as aself-powered gas sensor. Sens. Actuators B Chem. 2016, 222, 78-86. [CrossRef]

18. Shim, J.C.; Chung, G.S. Fabrication and Characterization of Pt/ZnO NO Sensor Integrated SiC Micro Heater. In Proceedings of the 2010 IEEE Sensors, Kona, HI, USA, 1-4 November 2010; pp. 350-353.

19. Weber, M.; Kim, J.Y.; Lee, J.H.; Kim, J.H.; Iatsunskyi, I.; Coy, E.; Miele, P.; Bechelany, M.; Kim, S.S. Highly Efficient Hydrogen Sensors Based on Pd Nanoparticles Supported on Boron Nitride Coated ZnO Nanowires. J. Mater. Chem. A 2019, 7, 8107. [CrossRef]

20. Deshwal, M.; Aurora, A. Enhanced acetone detection using Au doped ZnO thin film sensor. J. Mater. Sci. Mater. Electron. 2018, 29, 15315-15320. [CrossRef]

21. Lupan, O.; Cretu, V.; Postica, V.; Ahmadi, M.; Cuenya, B.R.; Chow, L.; Tiginyanu, I.; Viana, B.; Pauporte, T.; Adelung, R. Silver-doped zinc oxide single nanowire multifunctional nanosensor with a significant enhancement in response. Sens. Actuators B Chem. 2016, 233, 893-903. [CrossRef]

22. Yin, Z.; Wang, X.; Sun, F.; Tong, X.; Zhu, C.; Lv, Q.; Ye, D.; Wang, S.; Luo, W.; Huang, Y.A. Aligned hierarchical $\mathrm{Ag} / \mathrm{ZnO}$ nano-heterostructure arrays via electrohydrodynamic nanowire template for enhanced gas-sensing properties. Sci. Rep. 2017, 7, 12206. [CrossRef] 
23. Narayanan, G.N.; Ganesh, R.S.; Karthigeyan, A. Effect of annealing temperature on structural, optical and electrical properties of hydrothermal assisted zinc oxide nanorods. Thin Solid Films 2016, 598, 39-45. [CrossRef]

24. Chawla, V.; Ruoho, M.; Weber, M.; Chaaya, A.A.; Taylor, A.A.; Charmette, C.; Miele, P.; Bechelany, M.; Michler, J.; Utke, I. Fracture Mechanics and Oxygen Gas Barrier Properties of $\mathrm{Al}_{2} \mathrm{O}_{3} / \mathrm{ZnO}$ Nanolaminates on PET Deposited by Atomic Layer Deposition. Nanomaterials 2019, 9, 88. [CrossRef] [PubMed]

25. Saoud, K.; Alsoubaihi, R.; Bensalah, N.; Bora, T.; Bertino, M.; Dutta, J. Synthesis of supported silver nano-spheres on zinc oxide nanorods for visible light photocatalytic applications. Mater. Res. Bull. 2015, 63, 134-140. [CrossRef]

26. Wang, T.; Bristowe, P.D. Controlling Ag diffusion in ZnO by donor doping: A first principles study. Acta Mater. 2017, 137, 115-122. [CrossRef]

27. Sholehah, A.; Pusparasmi, D.A.; Yuliarto, B. The application of zinc oxide layer as ethylene sensor. IOP Conf. Ser. Mater. Sci. Eng. 2019, 541, 012051. [CrossRef]

28. Kumara, E.R.; Kamzin, A.S.; Janani, K. Effect of annealing on particle size, microstructure and gas sensing properties of Mn substituted $\mathrm{CoFe}_{2} \mathrm{O}_{4}$ nanoparticles. J. Magn. Magnet. Mater. 2016, 417, 122-129. [CrossRef]

29. Majumdar, S. The Effects of crystallite size, surface area and morphology on the sensing properties of nanocrystalline $\mathrm{SnO}_{2}$ based system. Ceram. Int. 2015, 41, 14350-14358. [CrossRef]

30. Krivec, M.; Gunnigle, G.M.; Abram, A.; Maier, D.; Waldner, R.; Gostner, J.M.; Überall, F.; Leitner, R. Quantitative ethylene measurements with MOx chemiresistive sensors at different relative air humidities. Sensors 2015, 15, 28088-28098. [CrossRef]

31. Ding, J.; Zhu, J.; Yao, P.; Li, J.; Bi, H.; Wang, X. Synthesis of ZnO-Ag Hybrids and Their Gas-Sensing Performance toward Ethanol. Ind. Eng. Chem. Res. 2015, 54, 8947-8953. [CrossRef]

32. Liu, C.; Kuang, Q.; Xie, Z.; Zheng, L. The effect of noble metal (Au, Pd and Pt) nanoparticles on the gas sensing performance of $\mathrm{SnO}_{2}$-based sensors: A case study on the $\{221\}$ high-index faceted $\mathrm{SnO}_{2}$ octahedra. Cryst. Eng. Comm. 2015, 17, 6308-6313. [CrossRef]

(C) 2019 by the authors. Licensee MDPI, Basel, Switzerland. This article is an open access article distributed under the terms and conditions of the Creative Commons Attribution (CC BY) license (http://creativecommons.org/licenses/by/4.0/). 